ARTIGO

\title{
A produção e a circulação da cultura pelas fronteiras da escola indígena Xakriabá
}

\author{
Verônica Mendes Pereiral (D) \\ Ana Maria Rabelo Gomes" (D)
}

RESUMO

O objetivo deste artigo é refletir sobre a produção e a circulação da cultura nas escolas Xakriabá. Nesse processo, os professores de cultura nos interessam mais detidamente. O artigo é resultado de uma pesquisa que teve como opção teórico-metodológica a investigação etnográfica. Concluímos que a cultura se vem firmando como elemento central nas escolas Xakriabá e a presença desses professores corrobora esse fato. A instituição, assim como as práticas desses professores, deixa claras a intenção e a presença de uma reinvenção do lugar da escola entre os Xakriabá: um lugar de fazer circular a sua cultura e a "cultura". Dessa forma, a escola passa a ser também espaço de mostrar aos outros a indianidade Xakriabá.

PALAVRAS-CHAVE

cultura; escola; educação escolar indígena. 


\title{
CULTURE PRODUCTION AND CIRCULATION THROUGHOUT XAKRIABÁ INDIGENOUS SCHOOL'S BORDERS
}

\begin{abstract}
This article's objective is to talk about culture production and circulation throughout Xakriabá indigenous schools. In this process, we have a closer interest on culture teachers. The article is the result of a research that had ethnographic investigation as its theoric-methodologic option. We concluded that the culture is setting itself as the central element in Xakriabâ's schools and that the presence of these teachers corroborates this fact. The institution as well as those teachers' practices make clear the intentions and the presence of a reinvention of the school's place among the Xakriabá: a place to circulate the "culture" and their culture. This way, the school also becomes a place to exhibit others Xakriabâ's indianity.
\end{abstract}

KEYWORDS

culture; school; indigenous school education.

\section{LA PRODUCCIÓN Y LA CIRCULACIÓN DE LA CULTURA POR LAS FRONTERAS DE LA ESCUELA INDÍGENA XAKRIABÁ}

\section{RESUMEN}

El objetivo de este artículo es reflexionar sobre la producción y la circulación de la cultura en las escuelas indígenas Xakriabá. En este proceso, los profesores de Cultura nos interesan más debidamente. El artículo es el resultado de una pesquisa que tuvo como opción teórico-metodológica la investigación etnográfica. Concluimos que la cultura se viene formándose como un elemento central en las escuelas Xakriabá, y que la presencia de esos profesores corrobora ese facto. La institución, así como las prácticas de estos profesores, dejan claras la intención y la presencia de una reinvención del lugar de la escuela entre los Xakriabá: un lugar de hacer circular su cultura y "la cultura". De esta manera, la escuela se convierte, también, en un espacio de presentar a los otros la indianidad Xakriabá.

\section{PALABRAS CLAVE}

cultura; escuela; educación escolar indígena. 
Este artigo apresenta parte de pesquisa que procurou analisar a produção e a circulação da cultura nas escolas Xakriabá, com base na implementação e na contínua expansão da escolarização no território indígena desse povo (Pereira, 2013). Nesse processo, os chamados professores de cultura nos interessaram mais detidamente, pela função singular e estratégica que assumem com relação à produção e reprodução de práticas culturais.

Localizados em um território que faz limites com os municípios de São João das Missões e Itacarambi, no Alto Médio São Francisco, e com uma população de cerca de 10 mil habitantes, os Xakriabá possuem uma área de aproximadamente 60 mil hectares e são, atualmente, o povo indígena mais numeroso de Minas Gerais. A sua história é marcada por fortes processos de mudança, dominação e integração sociocultural, assim como a de outros povos indígenas brasileiros, em especial os chamados índios do Nordeste (Santos, 1997).

Organizam-se, socialmente, contando com suas 33 aldeias e subaldeias, dispondo de um conselho composto de lideranças, cacique e vice-cacique, os quais, além de serem os responsáveis pela solução dos conflitos internos, representam a comunidade em eventos externos.

Desde a década de 1990, que marca o início da escola indígena Xakriabá, encontramos um movimento no sentido de que a escola, de alguma forma, precisava confrontar-se com algo para além do currículo escolar em senso estrito, e isso assume em dado momento a forma de que é a cultura que tem que entrar na escola (conferir, entre outros, Gomes, 2000). E quando os próprios índios nomeiam esse algo como sendo a cultura Xakriabá.

A insistência desse povo nas agências governamentais para a efetivação do cargo de professores de cultura nos permite afirmar que há um complexo e dinâmico processo de apropriação entre os indígenas e as instituições "vindas de fora" (conferir também Tassinari, 2001b, p. 161). A esse respeito, Ivenira, diretora da Escola Riacho dos Buritis, destaca o processo de negociação na Secretaria Estadual de Educação de Minas Gerais (SEE/MG) para a contratação dos professores de cultura: foi uma briga para valorizar e para que recebessem igual aos outros ${ }^{1}$ (Anotaçôes de Campo, julho de 2011). Afinal, os professores de cultura não tinham formação escolar.

Observamos nas escolas uma intensificação na produção e na circulação de práticas e conteúdos identificados como cultura Xakriabá, considerando a presença de vários de seus professores (de cultura, de arte, de uso do território e de práticas culturais); portanto, não será apenas nas aulas dos professores de cultura que vamos encontrar esse movimento. Neste texto, buscamos recompor o percurso que transformou "a cultura" em algo a "ser trazido" para a escola pelos professores de cultura, assumindo a cultura que procuramos identificar como aquilo que é veiculado por esses profissionais em suas práticas. Aqui lançamos mão da noção de cultura com aspas, tal como proposta por Carneiro da Cunha (2009), quando o conceito antro-

1 Será utilizado o itálico quando se tratar de expressões que circulam localmente, usadas pelos Xakriabá para tratarem dos temas aqui abordados. 
pológico é declinado nas práticas locais e assume características específicas quanto à sua significação e quanto àquilo que é colocado em circulação enquanto "cultura".

Em contrapartida, foi participando desse processo com outras/outros formadoras/formadores e pesquisadoras/pesquisadores, atuando há mais de 20 anos com esse povo, que nos perguntamos como a escola diferenciada tem acontecido. Nesse sentido, é muito pertinente refletirmos sobre o papel dos professores responsáveis pela produção e circulação da cultura e, em especial, dos professores de cultura, como um potencial para pensarmos a proposta da educação escolar indígena. Ainda mais se consideramos que "os conteúdos" ministrados por esses professores já nascem com o aval da diferença, uma vez que foram propostos para serem trabalhados por professores que, em sua maioria, apresentam pouca ou nenhuma escolaridade, além de serem "conteúdos" que paradoxalmente não se enquadram no modelo escolar canônico. Por fim, se considerarmos que os professores de cultura são aqueles que estão na escola, mas não vieram dela e nem precisam ficar nela, pois suas aulas acontecem em diferentes espaços no território indígena.

\section{A ESCOLA INDÍGENA XAKRIABÁ}

Em Minas Gerais, foi a partir de 1995 que a SEE, em convênio com a Universidade Federal de Minas Gerais (UFMG), a Fundação Nacional do Índio (FUNAI) e o Instituto Estadual de Floresta (IEF), iniciou o Programa de Implantação das Escolas Indígenas de Minas Gerais (PIEI), cujo objetivo era implementar escolas em quatro territórios indígenas habitados por quatro etnias reconhecidas pelo Estado até aquele momento, a saber: Krenak, Maxakali, Pataxó e Xakriabá.

É importante mencionar que antes do PIEI as aulas das poucas escolas das terras indígenas estavam a cargo de educadores leigos e, em sua maioria, não índios.

Assim, em 1996, teve início o primeiro curso de magistério indígena, com a participação de 66 índios, todos escolhidos por suas comunidades. $\mathrm{E}$ em outubro de 2000, o PIEI/MG inaugurou nova turma de formação, dessa vez com a presença de outras etnias, sendo elas: Kaxixó, Pankararu, Xucuru-Kariri, além de Xakriabá e Pataxó. Uma terceira turma finalizou o curso em 2008. ${ }^{2}$

No início do PIEI/MG, a meta era implementar escolas de $1^{\mathrm{a}}$ a $4^{\mathrm{a}}$ séries, mas a extensão das séries foi inevitável, de maneira que em 2000 teve início a $5^{\mathrm{a}}$ série e, em 2005, chegou-se ao ensino médio, além da abertura da educação infantil em 2006.

Atualmente são 34 escolas em funcionamento, sendo todas estaduais e não mais vinculadas ao município, como acontecia até o início da década de 1990. Funcionam nas aldeias espalhadas pelo território, atendendo a mais de 2.500 alunos, da educação infantil ao ensino médio. Duzentos professores, escolhidos por suas comunidades, assim como diretores e coordenadores indígenas, além de atuarem na educação escolar de suas crianças, gerenciam também suas escolas e definem o seu próprio processo educacional.

2 Entre os anos de 1996 e 2008 foram habilitados 213 professores das 7 etnias do estado que contam com escolas indígenas (Secretaria Estadual de Educação, 2013). 
A Figura 1 evidencia a evolução da matrícula nas escolas Xakriabá ao longo de 16 anos, isto é, entre 1997 e 2013:

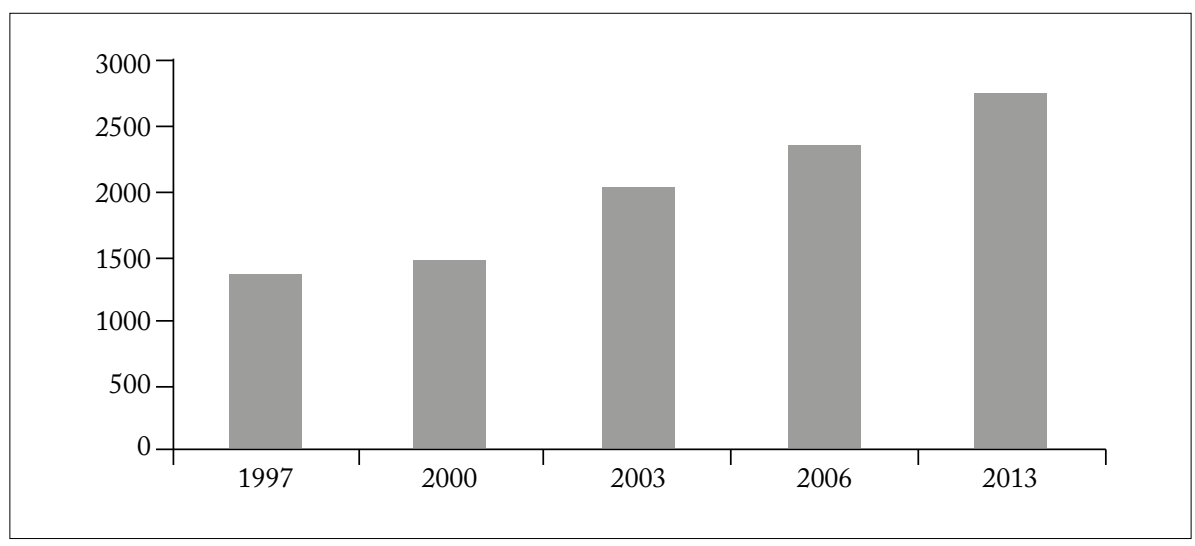

Figura 1 - Número de alunos matriculados ao longo dos anos.

Fonte: Secretaria Estadual de Educação de Minas Gerais (jan. 2013).

E a expansão dessa escolarização ainda é crescente. Em 2006, 110 professores Xakriabá iniciaram o ensino superior na UFMG, no programa especial de Formação Intercultural para Educadores Indígenas (FIEI), sendo diplomados em 2011. A partir de 2009, o FIEI configurou-se como um curso de oferta regular da Faculdade de Educação da UFMG, com ingresso anual de 35 indígenas. Além disso, está em funcionamento desde 2010 o Programa de Acesso e Permanência dos Estudantes Indígenas na UFMG, com 12 vagas anuais para os diversos cursos dessa universidade em processos seletivos realizados até 2013.

Constatamos que, com a existência de 34 escolas dentro do território Xakriabá, suas unidades vão construindo-se em seu cotidiano de maneira diferenciada. Há, em cada uma, algo de particular, que é dado pela interação dos atores nelas envolvidos: professores, alunos, comunidade, formadores, Estado, universidade. Nesse sentido, devemos entender as escolas Xakriabá, ou, melhor dizendo, cada escola Xakriabá, como uma construção social que mesmo imersa em um movimento histórico de amplo alcance é sempre uma versão local e particular desse movimento.

Assim é que as diferentes versões locais da escola Xakriabá nos conduzem a caminhos que se revelam na maneira como atuam seus professores, em especial os de cultura. Afinal, cada escola articula o seu discurso sobre "a cultura", que se expressa também nas diferentes práticas de seus professores. Assim, pensar os professores Xakriabá e suas escolas é pensar, também e o tempo todo, em similitudes e diferenças.

\section{DIMENSÕES DA “CULTURA” NA ESCOLA XAKRIABÁ}

Desde o nosso encontro inicial com os Xakriabá, em meados da década de 1990, já nos deparávamos com uma matriz orientadora de educação escolar baseada na experiência das escolas que já haviam funcionado naquele território, e também 
pela circulação de alguns poucos sujeitos por escolas da região. E, sem dúvida, "toda esta experiencia escolar, vivida en la década de los 70 y 80, acaba por formar parte, explícita o implícitamente, del proyecto que en los 90 empieza a construirse bajo el nombre de la escuela indígena diferenciada" (Leite, 2002, p. 269).

Muito embora as experiências da primeira matriz escolar Xakriabá tenham deixado fortes marcas do que seja o funcionamento de uma escola, é importante observar que tão logo a possibilidade da construção de uma escola indígena diferenciada entrou em pauta, ela passou a ser engendrada inicialmente pelos que estavam mais diretamente com ela envolvidos e, posteriormente, pelas pessoas da comunidade em geral, como um lugar para o resgate da cultura (Santos, 2010).

Orientados por essas duas matrizes, os Xakriabá foram, aos poucos, constituindo o fato de que a cultura seria o elemento central que entraria para a escola, mas não sem as tensões inerentes à relação entre forma escolar (Vicent, Lahire $\mathrm{e}$ Thin, 2001) e o que poderemos chamar de forma Xakriabá, conforme nos mostra o depoimento acerca do desafio em se adequar os tempos escolares e os tempos cotidianos:

Para nós, é um desafio muito grande pensar em tempo escolar após tanto tempo de imposição. A escola, quando chega nas sociedades indígenas também invade tempos de aprendizagem que o povo já tinha. Temos feito um esforço para relacionar o uso e a concepção de tempo do nosso povo com o tempo escolar. (Xakriabá e Xakriabá, 2008, p. 36)

Desde então, o caminho trilhado por esses indígenas tem sido o de reinventar esse espaço escolar. E, sem dúvida, ter quatro professores (de arte, de uso do território, de práticas culturais e de cultura) responsáveis pela circulação da cultura na escola corrobora esse fato.

É com a "cultura" que a escola se vai transformar em instrumento político de demarcação e reafirmação da diferença. É por meio dessa escola que os Xakriabá, agora, podem mostrar de um número grande de pessoas (alunos e professores), a outro número grande de pessoas (a eles próprios e aos demais agentes com os quais interagem em continuação), as "coisas da sua cultura", reafirmando o seu reconhecimento como indígenas e pleiteando direitos.

\section{RESSIGNIFICANDO A ESCOLA: ENTRE “CULTURA" (COM ASPAS) E CULTURA ESCOLAR}

As reflexões trazidas por Rockwell (2000), ao abordar a cultura escolar, ajudam-nos a pensar a escola Xakriabá tanto em uma dimensão mais ampla, como na sua relação com as agências externas, quanto em uma dimensão mais local, em que aparecem as suas especificidades. A autora afirma que as culturas são diferenciadas em relação à utilização dos espaços-tempos, sendo relevante a maneira pela qual os sujeitos se apropriam da escola, produzindo ressignificações que são impregnadas de seu fazer cotidiano. Por meio da abordagem da dimensão histórica da complexa vida escolar, a sua proposta orienta o nosso olhar para a cotidianidade escolar atual como cultura acumulada e em criação. 
A autora propõe a utilização de três planos para a abordagem da cultura escolar que nos possibilitam refletir sobre as diferentes temporalidades presentes nas culturas: o de longa duração, o da continuidade relativa e o da coconstrução cotidiana.

O terceiro plano proposto por Rockwell (2000), o da coconstrução cotidiana, que aqui é o que nos interessa, situa-se na reinvenção, na recriação cotidiana da cultura, no sentido de que professores e alunos reproduzem e recriam as culturas escolares, no próprio trabalho cotidiano da escola. A autora afirma que é possível dizer que a partir do encontro com a cultura herdada, se produz nova cultura, novos significados, novas práticas. Assim, a reinvenção dos espaços escolares é sempre um processo local. No plano da coconstrução cotidiana, o movimento é sempre duplo. Não se trata somente de transmitir a cultura. No encontro entre gerações, adultos, crianças e jovens recriam novas formas e elementos culturais.

Os Xakriabá, ao instituírem seus professores de cultura, trazem-nos a ideia de reinvenção que encontra ressonância nesse terceiro plano proposto por Rockwell (2000). Afinal, não seria essa uma reinvenção da cultura escolar bastante própria e específica? E essa reinvenção do processo educativo, pelos professores de cultura, por sua vez, encontra alguma ressonância no que nos diz Carneiro da Cunha (2009) sobre "cultura" (com aspas). Segundo a autora, a "cultura" "tem propriedade de uma metalinguagem: é uma noção reflexiva que de certo modo fala de si mesma" (Carneiro da Cunha, 2009, p. 356). Para a autora, "cultura" é um distintivo na maneira de se diferenciar dos outros. Nessa perspectiva, conforme ressalta Grupioni (2013, p. 76), a escola indígena tem assumido o lugar de "afirmar a diferença por meio de enunciados a respeito da indianidade”. Pois bem, com base nas noções aqui colocadas, não podemos inferir que o professor de cultura é aquele que se distingue dos outros professores? E que, em última instância, é um elemento diacrítico, que pretende distinguir, diferenciar a escola indígena Xakriabá.

\section{“LEVANTAR A CULTURA"}

De acordo com Santos (2010, p. 130), os professores de cultura surgem nas escolas Xakriabá como ícones do ensino diferenciado e, mais que isso, como atores importantes no processo de levantamento da cultura. Constatamos, em conversa com o Sr. José, um dos antigos mentores dos novos professores de cultura, que são esses os professores que procuram resgatar as coisas antigas: eles são diferentes dos outros, porque valorizam as coisas antigas (Sr. José Souza Freire, Anotaçôes de Campo, 2011).

O depoimento supracitado nos faz refletir sobre um fenômeno recorrente nos discursos de vários povos indígenas, que é a manutenção das tradições por meio da escola. Em última instância, os indígenas estão inventando mecanismos para lidar com essa instituição, ao criar e preservar fronteiras no contato com esse agente outro que é a escola.

Ao se referir à escola indígena como fronteiras, em uma clara oposição aos que defendem a ideia de que ela é apenas uma "frente ideológica, que demole tradições", há o "outro lado da moeda": "o da agência indígena e das suas formas de reordenar a experiência escolar e de reinterpretar os conhecimentos advindos com 
a escola" (Tassinari, 2001a, p. 58). E, ainda que considere a existência de "zonas interditadas", que são aquelas que evidenciam a "imponderabilidade" entre alguns conhecimentos indígenas e os conhecimentos escolares, há "os conhecimentos advindos da escola, que se articulam com as expectativas e com as visões de mundo indígenas, assim como certos conhecimentos indígenas que são mais facilmente incorporados ao currículo escolar" (Tassinari, 2001a, p. 66).

Se considerarmos a centralidade que a escola adquiriu na vida dos Xakriabá, possivelmente vamos concordar que esta acabou sendo também um espaço fundamental para a produção e a circulação da cultura e da "cultura", ainda que de maneiras muito diversas, pois os conteúdos dessas aulas estão estritamente ligados às práticas dos professores, que variam muito: se ele for um bom entendedor dos cantos, estará aí a centralidade de suas aulas, bem como se for um bom tocador de sanfona, e assim por diante, com relação às brincadeiras, aos jogos de versos, ao artesanato, à medicina tradicional. Não importam quais sejam esses conhecimentos, esses professores partem sempre do que sabem mais, dentro do que denominam as coisas da cultura.

É, pois, essa escola, construída nessas bases, que tem sido fonte importante para o levantamento da cultura, em termos bastante amplos. A sua reinvenção acontece cotidianamente, na mesma medida em que reinventam também a sua cultura indígena. Uma cultura que, pelo processo histórico dos Xakriabá, foi perdida mediante um processo de "violência física e simbólica" (Santos, 2010) e que tem sido por eles retomada ou, nos termos desse povo, levantada, como nos afirmam recorrentemente.

Portanto, com base nessa ideia, pensar o levantamento da cultura entre os Xakriabá é pensar na relação com o Outro e no englobamento daquilo que é externo. $\mathrm{O}$ contato com os variados agentes, com os quais eles lidam, proporciona a própria retomada da cultura, seja pela definição nativa do que seria parte da cultura, seja na captura de elementos outros para dentro da cultura.

Os esforços para tal empreitada têm sido muitos. Desde projetos sociais, que resgatam as nascentes, as sementes crioulas, os modos tradicionais de fazer a farinha, a rapadura, entre outros, até projetos das noites culturais, que têm como emblema maior a Casa de Cultura, ${ }^{3}$ espaço utilizado para as várias iniciativas de levantamento da cultura.

Esse levantamento, a partir da relação com o Outro, traz em seu cerne a invenção e a criatividade (Wagner, 2010). É importante ressaltar que as transformações são inerentes à própria definição de cultura. Portanto, a cultura não é um conjunto de elementos fixos e o processo de troca entre culturas inclui perdas, mas também acréscimos, e a sua vitalidade deve-se aos novos elementos que ela incorpora (Gallois, 2006).

A partir da Constituição brasileira de 1988, que garante uma educação que respeite as línguas, as culturas, os modos próprios de viver e pensar dos indígenas, assim como a valorização de seus conhecimentos e dos processos próprios de sua

3 A Casa de Cultura Xakriabá, construída na aldeia Sumaré, foi fruto de uma cooperação entre o Istituto Sindacale per la Cooperazione e lo Sviluppo (ISCOS, Modena, Itália), as Associações Indígenas Xakriabá (AIXs) e a UFMG. Ver detalhes em Santos (2010). 
produção e transmissão, mudou-se a perspectiva da escola, antes identificada como civilizatória para os índios, para a escola como direito. Essa mudança estruturou-se pela negação da escola vigente e pela formulação de um novo conjunto de premissas que deveriam orientar a sua transformação.

Ao analisar essa mudança, na qual o direito à educação escolar indígena específica passa a compor a agenda das políticas públicas, Grupioni $(2008$, p. 63) faz uma crítica importante ao entendimento equivocado dos agentes institucionais que vincularam as escolas indígenas ao sistema nacional, cumprindo a meta, entendida por eles, pela busca da equidade, mas deixando de lado o que realmente importava, ou seja, o exercício da diferença.

Mas não temos dúvida de que a escola indígena diferenciada "possibilitou aos índios um encontro inusitado com suas próprias culturas”(Grupioni, 2008, p. 218). No caso dos Xakriabá, não seria excessivo afirmar que ela tem sido importante para a produção e circulação da cultura, como nos confirma o professor de arte Vanginei:

A implantação da educação indígena diferenciada de Minas Gerais, a partir de 1996, com a intensa participação dos mais velhos, tanto das etnias de Minas quanto de outras etnias do Brasil, e palestras que muito conscientizaram todos os participantes, e, certamente, o contato com outros povos, fez com que todos voltassem a refletir sobre a cultura. Hoje, a pintura, as danças, as músicas e não só os usos de adereços, mas também a produção estão muito fortes no dia a dia dos Xakriabá. Estamos trabalhando intensamente com o objetivo de divulgar essa arte, através de pesquisas de cada estudante, em grupo ou individual. (Anotaçôes de Campo, 2011)

Os elementos contidos no depoimento do professor Vanginei são bastante profícuos para entendermos parte do que buscamos elucidar neste trabalho. A afirmação de que as palestras das quais participaram "conscientizaram todos os participantes" nos mostra o quanto a participação, a troca e a convivência entre os Xakriabá e os "de fora" não só acontecem, mas são consideradas algo positivo. Ou, se não positivo, inevitável, e passível de elaborações por parte deles. E, com certeza, a noção de cultura que hoje circula entre os Xakriabá advém, em boa parte, dessa convivência com outros agentes, que nesse caso tem sido, nas últimas décadas, bastante estreita e sistemática. E essa noção, que se constrói no contato interétnico, nos encaminha para a ideia de reflexividade (Wagner, 2010), conforme mostra a sequência do depoimento de Vanginei, que curiosamente usa o termo refletir como consequência do contato. Ele nos diz que "o contato com outros povos fez com que todos voltassem a refletir sobre a cultura".

A trajetória histórica dos Xakriabá nos encaminha para o entendimento de que a sua relação com o Outro sempre se deu por meio de um processo constante de mistura, que produz identidade e alteridade mediante a incorporação das coisas e das pessoas de fora. "Em seu contato com uma série de Outros, os Xakriabá são confrontados com o conceito antropológico de cultura em suas diversas expressões" (Santos, 2010, p. 77-78), e, nesse sentido, é preciso pensar os Xakriabá como um exemplo de reflexividade antropológica, de uma antropologia transformada e 
pensada ao modo nativo. Um indicador recente e muito significativo dessa transformação é a primeira dissertação de mestrado defendida por uma pesquisadora Xakriabá - Célia Nunes Correa - cujo título é revelador: O barro, o genipapo e o giz no fazer epistemológico de autoria Xakriabá: reativação da memória por uma educação territorializada, defendida na Universidade de Brasília (UnB), em 2018, apresentando o objetivo de refletir sobre os saberes e os fazeres presentes na Terra Indígena Xakriabá (TIX), com base em análises de experiências em educação indígena antes e depois da presença da escola na aldeia. De acordo com a autora, o título "se refere ao trânsito de ciclos de saberes que envolve as diferentes agências (e agentes) pelas quais se produz o conhecimento, constituindo um fazer epistemológico de autoria Xakriabá” (Correa, 2018, p. 9).

Portanto, assim como a compreensão da diferença, construída por meio da antropologia, ocasiona a constante e permanente (re)elaboração do conceito de cultura, é razoável pensar que os Xakriabá, ao refletirem sobre cultura estão também elaborando (ou inventando) a sua própria noção de cultura.

Nesse sentido, trata-se de um processo nos termos da "cultura como invenção" (Wagner, 2010). Ou seja, o que fazem os Xakriabá? Inventam uma noção de cultura (e tão carregada de ambiguidades quanto aquela com a qual a antropologia se vem debatendo desde o seu nascimento). Aqui, é importante ressaltar que estamos entendendo que "a lógica interétnica não equivale à submissão à lógica externa, nem à lógica do mais forte. É antes um modo de organizar a relação com estas outras lógicas" (Carneiro da Cunha, 2009, p. 356). É assim que devemos perceber a relação dos Xakriabá com os agentes com os quais convivem, ainda que nessa relação exista, sim, uma hierarquia que em muitos momentos os deixe em desvantagem.

Os Xakriabá criam seu mundo na medida mesma em que criam sua cultura. Verificamos que há uma intrínseca relação entre "cultura" e cultura escolar, pois vimos como a escola indígena é um espaço de "intercâmbio entre práticas e teorias, de encontro entre dois mundos, duas formas de saber, entre as tradições de pensamento ocidental e as tradições indígenas" (Tassinari, 2001a, p.49), ou seja, um espaço de disputas, de tensões, de paradoxos. Espaço seletivo, no qual são postos em circulação alguns saberes e práticas, e excluídos outros.

Podemos afirmar ainda que, nesse processo, os Xakriabá também reinventam a escola. Tassinari (2001a, p.49), apesar de reconhecer que a implantação de escolas indígenas introduz cargos e salários e certa hierarquia escolar (diretores, professores, merendeiras etc.) que reordenam ou, em alguns casos, reforçam as hierarquias locais, não concorda com o fato de a escola ser "apenas" isso. Para a autora, há o lado da agência indígena e das suas formas de reordenar a experiência escolar e de reinterpretar os conhecimentos advindos da escola (Tassinari, 2001a, p. 58).

Entre os Xakriabá, a implementação da escola indígena levou a uma série de modificações locais, verificadas pela introdução sistemática dos salários dos funcionários das escolas em um território no qual não havia nenhum outro tipo de trabalho assalariado. E, entre as muitas mudanças que vêm ocorrendo nesse território indígena, há o retorno de pessoas e famílias, especialmente jovens, que se deslocavam para as cidades, assim como um processo inicial de retomada das atividades econômicas dentro das aldeias. 
Contudo, o impacto não foi "apenas" nesses aspectos. Percebemos o sentido da agência indígena na retomada de aspectos tradicionais da identidade étnica, que encontra ressonância justamente na escola. É, portanto, nesse novo panorama no qual se mesclam aspectos da inserção em um mundo globalizado, aspectos da autodefinição identitária e a busca pela autogestão - que se articulam as novas possibilidades apresentadas às crianças e aos jovens Xakriabá (Pereira, 2011, p.366).

\section{OS PROFESSORES DE CULTURA}

Ao todo, temos nas escolas Xakriabá 13 professores de cultura atendendo a 7 das 33 escolas do território, sendo o Sr. Emílio Xakriabá o pioneiro, a pessoa que, de certa forma, inaugurou essa ideia entre eles. E, além de ser o mais antigo professor de cultura, é também o mais velho deles, que participou da luta pela terra, com o falecido e emblemático cacique Rodrigo.

Conforme nos descreveu, Sr. Emílio começou trabalhando nas escolas das aldeias Brejo do Mata Fome, Riachinho, Pedra Redonda, Riacho Comprido e Riacho do Brejo. Apesar de não se lembrar de quando começou, algumas pessoas nos disseram que foi em 2005. Nessa época, trabalhou por seis meses e depois se afastou: eu não dava conta e todo mundo me queria pra eu dar aula em todo canto. Em seu depoimento, ele explica como foi o processo de entrada dos novos professores de cultura e de como foi a sua participação nesse processo:

Sr. Emílio: Ai pra eu voltar foi preciso fazer uma pressão pra arrumar os outros pra dar aula. Fiz essa pressão com todo mundo da educação, da saúde, da UFMG, da Secretaria de Educação aqui de Januária. Porque eu sozinho não dava conta, porque a reserva era grande. Falei que só ia trabalhar se arrumasse mais professor, e o povo falou que só ia trabalhar se eu fosse trabalhar também. Eu prometi de ajudar eles, indicar eles como é que era a aula de cultura.

Pesquisadora: Que tipo de coisas eram essas que você indicava aos professores?

Sr. Emílio: A aula de cultura é a consideração do respeito, da tradição, do conviver, como era a nossa doutrina Xakriabá, como é que nós tratava os outros, como nós comi, como nós vivia, como nós dormia, isso tudo a gente ia contando, qual era o respeito que a gente tinha pelo outro. (Anotaçóes de Campo, 2011)

D. Dalzira é outra professora que nasceu na aldeia Pindaíbas e vive, desde que se casou, na subaldeia Veredinha. É filha de José, que também nasceu na TIX, e de Dominga, que veio de Borrachudo, um povoado que fica perto do território. Seu avô materno nasceu na aldeia do Brejo, assim como seus bisavós maternos. De acordo com D. Dalzira, sua avó era cabocla, e seus avós paternos, Dizidério e Geralda, tinham alambique, casa de farinha e eram envolvidos com o "Reis": Esse Reis passava na Pindaíbas todo ano. Hoje, quem dá continuidade ao Reis do Velho Ozébio, irmão do meu avô, é Manoel de Catulé, que também é professor de cultura na aldeia Riacho dos Buritis. 
Ela é uma das mulheres ceramistas do TIX e, além de tocar zabumba, também participa dos Reis. Faz pequenas esculturas em madeira, atividade que ela começou, ainda jovem, utilizando cera de abelha, com que ela esculpia pequenos bichos e peças para enfeitar presépios. ${ }^{4}$

Começou a dar aulas de cultura em 2007, na Escola Xukurank, que tem sede na aldeia Barreiro. Mas, além dessa escola, também dá aulas na escola da subaldeia Veredinha, bem perto de sua casa. Quando iniciou sua função como professora de cultura, trabalhava com os alunos dos turnos da manhã e da noite, mas com a chegada da professora Laura, também de cultura, o horário foi dividido.

Laura começou a dar aula de cultura em 2007. É professora da Escola Xukurank, e dá aula nas aldeias Olhos D’Água, Brejinho e Barreiro. Ao perguntá-la por que eles queriam que ela fosse a professora, Laura nos disse:

É porque desde pequena eu já fazia, inventava tudo quanto é coisa, fazia cachimbo de coco, e qualquer coisa que falasse, assim... "Eu vou fazer isso", eu fazia, né? Costura, tudo... Ai chegava uma pessoa aqui: "- Eu tenho uma coisa aqui pra fazer, não tô conseguindo". Ai eu: "-Dá jeito". Ai tudo eu ia consertando e fazendo. Ai falou: "Não... Acho que aqui é você mesmo". Ai eu falei: "-N Não, tenho muita prática pra isso não". "- Mas vai aprendendo devagarzinho". Ai eu tô aí, né, trabalhando na escola, gostando muito. É um serviço bem cansativo, que tudo tem que sai da cabeça, num é um plano, assim, que pega do livro e pensa, e amanhã vou fazer o quê... Um bucado de coisa que a gente inventa na hora lá, o dia que não tem nada pra fazer, assim, écolar, cocar, tudo a gente ensina fazer, brinco, charri. [enfeite de cabelo feito de penas] [...] Eu toco zabumba, pandeiro, o chique-chique, e reque-reque da Folia de Reis. (Anotações de Campo, março de 2011)

Laura é irmã de Nicolau, professor de cultura da aldeia Sumaré I. Nicolau trabalha na associação do Barreiro desde 1998, fazendo parte da diretoria. Como a associação se ampliou, hoje ele trabalha com as aldeias Vargens, Sumaré I, II e III, Custódio e Caatinguinha. Essas associações são concentradas na do Barreiro, ainda que hoje as aldeias Sumaré I e II tenham associação, mas são sócias na do Barreiro também.

O primeiro projeto com o qual Nicolau trabalhou foi a Casa de Farinha. Foi esse projeto que serviu de pontapé ou, como disse Nicolau, de rascunho para os outros que viriam,

Porque a linguagem era a mesma, só mudava a questão da comunidade e o que era o projeto, se era casa de farinha, se era um engenho, mudava só assim. Ai vinha aquelas

4 D. Dalzira contou uma história interessante sobre como, ainda criança, começou a lidar com o barro. Uma de suas funções para ajudar a família era ir para a roça vigiar as jandaias, uma espécie de periquito que atacava as plantações. Ela, enquanto passava o dia ali, pegava barro dos córregos e ia modelando bichinhos, de maneira que muitas vezes se esquecia das jandaias, o que deixava seu pai muito enfurecido. De acordo com D. Dalzira, foram várias as vezes que seu pai, de tão enfurecido, pisou em todos os seus bichinhos de barro. 
mesmas perguntas: qual a sucessão, qual a data que foi criada. A estrutura era a mesma, quais são os parceiros... (Anotações de Campo, 2011)

De acordo com Nicolau, algumas pessoas se preocuparam questionando se aquele novo cargo, de professor de cultura, não atrapalharia suas funções na associação, mas ele argumentou dizendo que o seu trabalho na associação era voluntário, e se o trabalho de professor de cultura vai ganhar, eu vou é ajudar a associação, pois se o trabalho é voluntário e eu nunca deixei ela, vai é ajudar. E continuou:

- O que ganha na associação não pode dizer que é salário, porque só na correria o dinheiro já vai embora; por exemplo, se eu fosse trabalhar o mês todo e fosse pegar aquele dinheiro e comprar alguma coisa, mas hoje, com aquele dinheiro, a gente tem que cobrir correria, é um gasto de transporte... As taxas hoje é 11 reais por mês, que os sócios paga, a gente tem que pagar contador, cartório, correio, $e$ tudo é caro, né? Ai, tem hora que a gente tira do bolso e cobre e nem olha pra trás, que dia que vai tirar aquele dinheiro, se vai sobrar... Ai, por isso que hoje, dentro da sala de aula, tem vez que eu passo até 15 dias, 1 mês, sem trabalhar dentro da sala de aula. Mas por quê?? Porque hoje o projeto de cultura, pela Secretaria de Cultura é a associação que tá recebendo. Às vezes tem coisa pra resolver no banco e eu que tenho que ir, tem coisa pra fazer, compra de coisa para os projetos, tem que ir. Acaba a gente fica envolvido e, hoje, só a escola não tá tendo quase nada para oferecer na área de cultura, né? Ai a gente tá conseguindo é com a Secretaria de Cultura, com as parcerias. É por isso que hoje mesmo eu tava na escola passando um video de um projeto que a gente executou lá no Custódio, passando foto a foto como é que a gente construiu. "Olha gente, só pra você vê: a construção é igual à vida da gente, ela hoje é uma coisa, amanhã já é outra". E se a gente não for registrando cada projeto hoje, você nem sabe como é que ele foi comę̧ado. Ai eu falo quantas vezes eu fico sem vir na sala de aula, aqui, mas a gente já tá retornando com o que a gente tava fazendo, os projetos. E aí hoje, na escola, eles já entende por que, né? (Anotaçôes de Campo, março de 2011)

Hoje, Nicolau está à frente de diferentes projetos em quatro aldeias. $\mathrm{Na}$ aldeia Vargens, com a farinheira, para produção de farinha; na subaldeia Custódio, também com a farinheira e com o projeto de roça comunitária. De acordo com o professor, lá foi feito 12 hectares de roça, tudo plantado. Na aldeia Caatinguinha, que está à espera da liberação de recursos para o engenho comunitário. E na aldeia Sumaré III, com uma farinheira e uma minipadaria, numa área de $8 \times 8$ de construção, com fogão, geladeira, congelador, forno. A agência financiadora desses projetos é a Carteira Indígena, vinculada ao Ministério do Meio Ambiente.

Além de estar à frente dos projetos mencionados, Nicolau é tocador de sanfona, com participação ativa nos Reis do TIX. Ele mantém contato com todos os professores de cultura, e em especial com Deda, da Escola Bukimuju, aldeia do Brejo, com quem se encontra sempre tanto para conversar como para fazer cocar, objeto que estão aprendendo a confeccionar juntos. Ele também se encontra muito 
com D. Dalzira e Laura, sua irmã, da Escola Xukurank. Mas a sua maior parceria é com o também professor de cultura Vicente.

Vicente é da aldeia Caatinguinha. Ele nos relatou que seu nome foi indicado para professor de cultura em virtude de sua estreita relação com pessoas de diferentes comunidades, pelo fato de ele ser um benzedor. Ele viajava muito e viveu durante muitos anos entre idas e vindas para o corte de cana, mas, como pajé, fazia falta, pois as pessoas chegava pra procurar a gente, a gente tava viajando. A sua aprendizagem com as plantas e as benzeções se deu na relação com seu avô, o também pajé Inocêncio, ${ }^{5}$ já falecido, e com o qual viveu desde os 7 anos. Ao ser perguntado sobre o fato de seu avô ter passado o cargo para ele, apesar de existirem outros netos, Vicente relatou: as pessoas que trabalham com esses trabalhos conhece a pessoa que serve para desenvolver...

Vicente contou que sua parceria de trabalho como professor de cultura é com o "Nico" (referindo-se a Nicolau), mas tem outros professores que ele procura, como Deda, da aldeia Brejo do Mata Fome, com quem ele sempre se encontra para fazer um trabalho junto.

Deda é também conhecido por José. Ele vive na aldeia Imbaúba e trabalha na Escola Bukimuju, na aldeia Brejo do Mata Fome. Ele confecciona o cordão de São Francisco, objeto da "antiga" tradição Xakriabá, portanto, sempre que morre alguém, a comunidade pede esse serviço a ele. Conforme ele nos disse:

[...] é um serviço bem forte, assim, é quando morre uma pessoa faz as oraçôes, essas orações a gente faz num cordão, chama cordão de São Francisco [...] o pessoal me fala e eu vou lá fazer esse cordão, que é de algodão. Isso foi passado por meu tio Miguel, ele me passou e falou pra eu trabalhar nessa parte.

Ele falou assim: "Eu acho que você está preparado para isso. Vou estar passando esse ensinamento, porque qualquer dia eu vou faltar, já ando doente, né? Não sei se vou poder fazer mais, então vou estar te passando o que aprendi de muito tempo, desde jovem". Ai me explicou como fazer, quantas oraçôes faz. Ai eu pensei: "Seja bem-vindo essa explicação, porque vou aprender!". (Anotaçôes de Campo, outubro de 2011)

Apesar de todos os professores pesquisados serem possuidores de alguma sabedoria e/ou envolvimento com as coisas da tradição, conforme aparece nos depoimentos, isso não significa que todos saibam as mesmas coisas, e, nesse sentido, vamos encontrar as especialidades das aulas de cada um dos professores de cultura. Os seus conteúdos e as suas práticas são diversificados, assim como o são os processos dentro da TIX.

Parece-nos imprescindível que o professor de cultura seja envolvido com alguma coisa da tradição, no sentido de que os mais velhos dão ao termo, como é o caso do professor Deda, que confecciona cordões de São Francisco; de Nicolau, que

5 O pajé Inocêncio é apresentado na dissertação de mestrado de Verônica Mendes Pereira (2003), que teve oportunidade de conhecê-lo pessoalmente. Sobre o tema da pajelança, ver Fernandes (2008). 
toca sanfona nos Reis; de Vicente, exímio conhecedor das plantas do tabuleiro; ${ }^{6}$ de D. Dalzira, antiga ceramista do TIX; ou de Laura, tocadora de zabumba nos Reis. Assim, temos uma clara demarcação da gramática interna Xakriabá, em que cada um vai contribuir com o que sabe fazer melhor pra comunidade, como declarou Nicolau.

Os professores de cultura com os quais conversamos afirmaram que eles "ensinam a cultura na prática", e na pesquisa de campo observamos muito dessa premissa. Com base no que ouvimos, passamos a considerar que há uma expectativa, principalmente entre os mais velhos, de que os professores de cultura trabalhem para fazer o diálogo entre os conhecimentos escolares e os conhecimentos tradicionais, da comunidade. Vários professores de cultura afirmaram que a função deles é ensinar a cultura na prática, chegando mesmo a dizer que essa é a grande diferença em relação aos outros professores.

Depreendemos que ser professor de cultura é estar apto a apreender as coisas da cultura, e não restritamente saber ou replicar as coisas da cultura. Podemos afirmar que esses professores foram escolhidos para ensinar a cultura na escola porque sabem das coisas que não podem ser ensinadas sobre ela, ou ainda porque têm potencial para tal:

- O professor de cultura valoriza essas coisas, as coisas antigas. Aprendem as coisas que os mais velhos valorizam, procuram aprender... Os professores de cultura conversam com os mais velhos para aprender. As novas bases devem trabalhar com as antigas. Tem que lembrar o passado. (Sr. José Souza Freire, aldeia Barreiro Preto, Anotaçôes de Campo, 2011)

- Treinar os mais novos para defender os direitos deles. Além dos remédios, o professor de cultura tem que ser um benzedor. Tem que ter confiança nos professores de cultura. Quando vamos nas cavernas, fazemos uma palestra na chegada e no final. Vai que um dia podem ser um cacique, uma liderança. (Sr. Valdemar, liderança da aldeia Prata, Anotações de Campo, 2011)

Essas diferentes práticas, circuladas por intermédio dos professores, mostram-nos duas questões importantes: por um lado, há uma diversidade de habilidades e expectativas presentes nessa função e, por outro, os lugares sociais que esses professores ocupam nas relações sociais, na organização política, nas formas de gestão do conhecimento e nas relações interétnicas. E, se as suas práticas são diversificadas, em última instância, os lugares que esses professores ocupam também o são.

Verificamos a confirmação da disponibilidade que deve apresentar o professor de cultura para procurar aprender e vincular-se aos mais velhos, bem como o papel que devem assumir os mais velhos nessa relação: treinar os mais jovens (na cultura) para defender os seus direitos, uma nítida relação das implicações entre cultura e política, relevante no depoimento do Sr. Valdemar, quando nos diz que esses professores podem vir a ser um cacique ou uma liderança, ou seja, podem assumir encargos políticos que respondem por negociações dentro do território e com os agentes externos.

6 Tabuleiro é definido pelo dicionário Houaiss como um terreno pouco elevado de solo arenoso e vegetação rarefeita. Aproxima-se da Caatinga e do Carrasco. Em termos locais, opõe-se à mata, é um terreno no qual se pode cultivar. 
Saber da cultura, mas também saber explicitá-la nos momentos e espaços adequados, é garantir direitos - e esta nos parece uma função importante desses professores como mediadores entre escola, comunidade e as agências com as quais lidam os Xakriabá. Portanto, fica bastante nítido que esse processo, da seleção à manutenção do professor de cultura, está envolto em uma clara expectativa da comunidade com relação a esses professores para funções de muita responsabilidade, no sentido da continuidade da tradição, entendida aí também como ato político. E podemos entender que é a "cultura", que eles fazem circular por meio da escola, a responsável por essa manutenção.

Foi a isso que assistimos nas aulas da professora Rosa, de práticas culturais, ao trabalhar as orações locais; nas aulas do professor Nicolau, de sanfona, de Reis, ou sobre os projetos sociais. Nas aulas de pintura corporal do professor Deda; nas aulas sobre remédios, do professor Vicente; de cerâmica, de D. Dalzira e Vanginei; e nas aulas de arte do professor Rânison, quando se aprende a tocar violão e a cantar músicas sertanejas. Esses são exemplos das diversas características do grupo pesquisado. Um grupo que historicamente se vai conformando na relação com o Outro e aí se reinventando.

\section{CONSIDERAÇÕES FINAIS: IDA Y VUELTA}

O termo cultura, já incorporado pelos Xakriabá, é sempre exaustivamente debatido em encontros, reuniões, formações, seminários... e nos quais, comumente, encontramos variados tipos de agentes, entre eles antropólogos, pedagogos, indigenistas, técnicos da SEE, entre outros. Portanto, aos antropólogos que responsabilizam apenas os educadores e pedagogos pela disseminação de versões "desatualizadas e ultrapassadas" do conceito, é bom lembrar que "[...] noções como raça e, mais tarde, cultura [...] foram difundidas pelos missionários do século XIX [...], mas num período mais recente foram os antropólogos os principais provedores da ideia de 'cultura', levando-a na bagagem e garantindo sua viagem de ida” (Carneiro da Cunha, 2009, p. 312).

Se por um lado essa ideia contribuiu para o levantamento da cultura, por outro volta para assombrar os remetentes que comungaram e reforçaram a ideia, como nos "cantes de ida y vuelta", anunciados por Carneiro da Cunha (2009). Afinal, a "cultura" (com aspas) se fixou de tal modo nos discursos indígenas que hoje, como propõe Carneiro da Cunha, ao operarmos com a cultura, temos que considerar a cultura e a "cultura" como duas categorias distintas, apesar de sua coexistência. A autora propõe o entendimento da noção de cultura e de cultura com aspas baseada na categoria de ida y vuelta, termo cunhado por ela tendo como referência a música flamenca, especificamente os gêneros que essa arte classifica como cantes de ida $y$ vuelta ${ }^{7}$ : "Cultura", e assim as noções de trabalho, dinheiro, higiene etc., são, todas elas,

7 É importante registrar que, para os flamencólogos e estudiosos do flamenco, os cantes de ida y vuelta são estilos musicais originalmente americanos que foram "aflamencados", provavelmente no final do século XIX, tornando-se palos ou estilos flamencos (Caballero, 1994, p. 187). 
bens ou males exportados inicialmente por missionários e, mais recentemente, por antropólogos, e são essas categorias que hoje retornam para assombrar aqueles que as produziram. São coisas que vão e voltam, como a ideia de ida y vuelta.

A instituição dos professores de cultura, nos moldes Xakriabá, não deixa de ser um fato bastante emblemático dessa ideia. De certa forma, a própria existência dessa categoria e a sua função, a de produzir e fazer circular a cultura na escola e para fora dela, já é uma maneira de explicitação dessa "cultura".

Tentar compreender a circulação da cultura nas escolas dos Xakriabá nos levou ao encontro dos professores responsáveis por essa circulação, a saber, os professores de uso do território, de práticas culturais, de arte e de cultura. Dentro desse cenário, nos detivemos, de maneira mais aprofundada, nestes últimos. Isso se deu por serem eles os que guardam especificidades muito próprias, caracterizadas por seus perfis e pela maneira como foram instituídos. Uma conquista que só se efetivou, é importante dizer, por meio de um longo processo de negociação na SEE/MG.

Os professores de cultura são os únicos das escolas Xakriabá para os quais não se exigiu (e não se exige) escolarização. Além disso, eles foram indicados para assumirem esses cargos em uma negociação direta entre a escola e os mais velhos das comunidades, processos bastante diferenciados daqueles vivenciados pelos demais professores, incluindo aí os outros professores, também responsáveis pela circulação da cultura nas escolas. Se a cultura se vem firmando como elemento central nas escolas Xakriabá, já há algum tempo não temos dúvida de que a presença desses professores corrobora esse fato. Nesse sentido, concluímos que essa escola tem sido, e cada vez mais, um locus importante para que tal circulação aconteça.

Considerando o vigor dessa presença, podemos dizer que esse tem sido um caminho encontrado pelos Xakriabá para fazer com que se efetive a sua escola indígena diferenciada. Não sem razão, vamos encontrar quatro categorias de professores responsáveis por trazer a cultura para a escola, desde as turmas de Período Preparatório de Alfabetização (PPA) até as de ensino médio, e com práticas muito semelhantes. É uma garantia de que a cultura está na escola e em todas as turmas, por intermédio de seus quatro professores e de seu ícone maior, o professor de cultura.

Nesse sentido, podemos perceber a escola Xakriabá como um espaço de reinvenção e recriação cotidiana da cultura, situada no plano da coconstrução cotidiana, como proposto por Rockwell. A instituição, assim como as práticas desses professores, deixa clara a intenção e a presença de uma reinvenção do lugar da escola entre os Xakriabá: um lugar de fazer circular a sua cultura ou a "cultura" (com aspas). Dessa forma, a escola passa a ser também espaço de mostrar aos outros a indianidade dos Xakriabá e pleitear direitos. Os Xakriabá também vivenciam o mesmo que outros povos, isto é, "a descoberta de que se antes todos tinham 'cultura em si', agora podem ter 'cultura para si' e exibi-la diante do mundo, demonstrando performaticamente essa cultura" (Carneiro da Cunha, 2009, p. 311-314).

Após tantos anos de convivência com os Xakriabá, verificamos mudanças significativas de ordens diversas acontecerem nesse território, e, sem dúvida, continuam a acontecer, operadas com a contribuição da implementação da escola 
indígena que nos vem mostrando caminhos inventivos para se fazer desse um lugar Xakriabá. É o caso da professora Célia Xakriabá, cujo trabalho de mestrado foi referido anteriormente, que, após a sua formação no FIEI, foi assumida como professora de cultura na escola de sua aldeia. Seu tema - pinturas corporais - foi promovido inicialmente pelo encontro, durante o curso, com um xamã Kaxinawá, que comentou o modo singular como ela apresentava as pinturas em seu corpo. Esse comentário a levou a se voltar para esse tema e a buscar mais informações nas aldeias e no próprio curso com os demais sábios indígenas que teve oportunidade de encontrar. A partir desse encontro, "seu trabalho tomou vulto e foi reconhecido pela liderança, que a convidou para assumir aulas como professora de cultura" (Gomes, 2014, p. 480-481).

Como nos afirma a própria Célia (Correa, 2018, p. 48):

Enxergamos na sabedoria dos mais velhos uma fonte de conhecimentos, temos a opção de deixar que esses conhecimentos passem por nós como chuva passageira ou podemos converter a nós mesmos em cacimbas que armazenam e guardam água para o tempo da necessidade. Assim, por meio de metáforas, é que se constitui os conhecimentos dos mais velhos que nos dizem mais ou menos assim: "A inteligência pode ser adquirida com o tempo da escola, já a sabedoria é outra temporalidade, exige um movimento maior da mente, mas também do corpo. Um conhecimento não é apenas elaborado pela mente, é elaborado também pelo exercício da prática com as mãos".

Como vimos, a construção da escola diferenciada entre os Xakriabá é marcada por uma enorme diversidade de aulas e práticas que, se por um lado guardam semelhanças, por outro se diferenciam em razão dos perfis dos professores. Diferenças e similitudes, tanto em relação aos conteúdos quanto à forma com que se propõem, em uma criação contínua de seu mundo e de sua cultura Xakriabá.

\section{REFERÊNCIAS}

CABALLERO, Á. Á. El cante flamenco. Madri: Alianza, 1994.

CARNEIRO DA CUNHA, M. Cultura com aspas. São Paulo: Cosac Naify, 2009.

CORREA, C. N. O barro, o genipapo e o giz no fazer epistemológico de autoria Xakriabá: reativação da memória por uma educação territorializada. 2018. Dissertação (Mestrado) - Programa de Pós-Graduação Profissional em Desenvolvimento Sustentável, Universidade de Brasília, Brasília, 2018.

FERNANDES, I. N. O uso de plantas medicinais e os processos rituais de cura entre os Xakriabá da aldeia Caatinguinha, São João das Missões, Minas Gerais. 2008. Monografia (Bacharelado em Ciências Sociais) - Faculdade de Filosofia e Ciências Humanas, Universidade Federal de Minas Gerais, 2008.

GALLOIS, D. T. (org.). Patrimônio cultural imaterial e povo indígenas: exemplos no Amapá e norte do Pará. São Paulo: Iepé, 2006. 
GOMES, A. M. R. Produção e reprodução da cultura escolar: algumas delimitações para a análise da experiência dos professores indígenas Xakriabá. Educação em Revista, Belo Horizonte, número especial, p. 37-68, 2000. Disponível em: http://educa.fcc.org. br/scielo.php?script=sci_arttext\&pid=S0102-46982000000200004\&lng=pt\&nrm=iso. Acesso em: 11 maio 2019.

GOMES, A. M. R. A formação de professores indígenas na UFMG e os dilemas das "culturas" entre os Xakriabá e os Pataxó. In: CUNHA, M. C.; NIEMEYER, P. C. (org.). Políticas culturais e povos indígenas. São Paulo: Cultura Acadêmica, 2014. p. 455-484. GRUPIONI, L. D. B. Olhar longe, porque o futuro é longe: cultura, escola e professores indígenas no Brasil. 2008. Tese (Doutorado) - Faculdade de Filosofia, Letras e Ciências Humanas, Universidade de São Paulo, São Paulo, 2008.

GRUPIONI, L. D. B. Quando a antropologia se defronta com a educação: formação de professores índios no Brasil. Pro-Posições, Campinas, v. 24, n. 2, p. 69-80, 2013. http://dx.doi.org/10.1590/S0103-73072013000200006

LEITE, L. H. A. Escuela, movimientos sociales y ciudadanía. 2002. Tese (Doutorado) - Faculdade de Filosofia e Ciencias de la Educación, Universidad de Valencia, Valencia, 2002.

PEREIRA, V. M. El impacto de la escolarización entre los Xakriabá: algunas reflexiones. In: PALADINO, M.; GARCIA, S. M. (org.). La escolarización en los pueblos indígenas americanos: impactos y desafios. Quito: Ediciones Abya-Yala, 2011. p. 349-369.

PEREIRA, V. M. A circulação da cultura na escola indígena Xakriabá. 2013. Tese (Doutorado) - Faculdade de Educação, Universidade Federal de Minas Gerais, Belo Horizonte, 2013.

ROCKWELL, E. Tres planos para el estudio de las culturas escolares: el desarrollo humano desde una perspectiva histórico-cultural. Revista Interações - Estudos e Pesquisas em Psicologia, São Paulo, v. 5, n. 9, p. 11-25, jan./jun. 2000.

SANTOS, A. F. M. Do terreno dos caboclos do Sr. São João à Terra Indígena Xakriabá: as circunstâncias da formação de um povo. Um estudo sobre a construção social de fronteiras. 1997. Dissertação (Mestrado) — Universidade de Brasília, Brasília, 1997.

SANTOS, R. B. C. A cultura, o segredo e o índio: diferenças e cosmologia entre os Xakriabá de São João das Missões/MG. 2010. Dissertação (Mestrado) — Universidade Federal de Minas Gerais, 2010.

SECRETARIA DE ESTADO DA EDUCAÇÃO DE MINAS GERAIS. [Formação Intercultural para Educadores Indígenas]. Belo Horizonte: 2013. Documento de circulação interna fornecido à coordenação do FIEI.

TASSINARI, A. M. I. Escola indígena: novos horizontes teóricos, novas fronteiras de educação. In: SILVA, A. L.; FERREIRA, M. K. L. (org.). Antropologia, história e educação: a questão indígena e a escola. São Paulo: Global, 2001a. p. 44-70.

TASSINARI, A. M. I. Da civilização à tradição: os projetos de escola entre os índios do Uaçá. In: SILVA, A. L.; FERREIRA, M. K. L. (org.). Antropologia, história e educação: a questão indígena e a escola. São Paulo: Global, 2001b. p. 157-195. 
XAKRIABÁ, M. G.; XAKRIABÁ, M. J. Um pé na aldeia, um pé no mundo. Belo Horizonte: UFMG/FAE, 2008. [Livro produzido no curso de formação intercultural de professores indígenas].

VINCENT, G.; LAHIRE, B.; THIN, D. Sobre a história e a teoria da forma escolar. Educação em Revista, Belo Horizonte, n. 33, p. 7-48, jun. 2001.

WAGNER, R. A invenção da cultura. Tradução de Marcela Coelho de Souza e Alexandre Morales. São Paulo: Cosac Naify, 2010.

\section{SOBRE AS AUTORAS}

Verônica Mendes Pereira é doutora em educação pela Universidade Federal de Minas Gerais (UFMG). Professora da Universidade Federal de Ouro Preto (UFOP).

E-mail: veronicamendes23@gmail.com

Ana Maria Rabelo Gomes é doutora em educação pela Università di Bologna (Itália). Professora da Universidade Federal de Minas Gerais (UFMG). E-mail: anagomes@fae.ufmg.br

Recebido em $1^{\circ}$ de maio de 2018 Aprovado em 15 de outubro de 2018 